\title{
INDICADORES DE SUSTENTABILIDADE, DEFINIDOS NO PADRÃO DE PRODUÇÃO BONSUCRO DE USINAS SUCROENERGÉTICAS DO ESTADO DE SÃO PAULO VISANDO O MERCADO EUROPEU
}

\author{
INDICATORS OF SUSTAINABILITY, DEFINED IN THE STANDARD OF \\ PRODUCTION BONSUCRO OF SUGARCANE PLANTS OF THE STATE OF SÃO \\ PAULO AIMING AT THE EUROPEAN MARKET
}

Prof. Me. André Luís Assumpção - andreluisassumpcao@ gmail.com Faculdade São Luís - Jaboticabal - São Paulo - Brasil

Profa. Dra. Glaucia Aparecida Prates - g.prates@ unesp.br

UNESP - Itapeva - SP - Brasil

Profa. Dra. Lesley Carina do Lago Attadia Galli - lesleyattadia@ fcav.unesp.br
UNESP - FCAV- Jaboticabal - SP - Brasil

Profa. Dra. Helenita Rodrigues da Silva Tamashiro - hrstamashiro@ibest.com.br Faculdade de Tecnologia (FATEC) - Sertãozinho -São Paulo - Brasil

\begin{abstract}
RESUMO
A sustentabilidade é um conceito adotado por vários setores produtivos, a qual busca atender critérios socialmente desejados/valoráveis e imposições legais e normativas. Dentro deste contexto existem certificações e legislações internacionais que direcionam estas exigências. A Diretiva 28/2009/CE do Conselho e Parlamento Europeu, publicada em 23 de abril de 2009 e a Bonsucro (Better Sugarcane Initiative) são bases importantes de informação. Diante desse contexto, o setor sucroenergético tem as suas práticas monitoradas por todo o mundo, e práticas produtivas inadequadas com esta nova realidade interfere na comercialização dos seus produtos. Entretanto, para possibilitar que os produtores brasileiros possam atender também a essas exigências externas, o Bonsucro, única certificação para biocombustíveis derivados de cana-de-açúcar implementada no Brasil incluiu algumas das exigências da União Européia. Associado à questão, o objetivo geral desse trabalho é demonstrar através de pesquisa bibliográfica sobre a importância de se analisar as lacunas de sustentabilidade baseados no Padrão Bonsucro para alcance do mercado Europeu de nossas unidades produtoras sucroenergéticas. Como conclusão tem-se: Paralelamente, a identificação dos avanços do setor rumo à sustentabilidade da produção de etanol, e dos obstáculos ainda existentes, conduzirá não só à proposição de ações que viabilizem as exportações, mas também ações para desenvolver parte do setor que não prioriza a exportação. O segundo aspecto, bastante desafiador, baseiase na proposta de avaliação das lacunas, e propor ações para o setor sucroalcooleiro quanto ao atendimento a requisitos que lhe favorecerão no acesso a mercados.
\end{abstract}

Palavras-chave: Sustentabilidade. Bonsucro. Sucroenergético. 


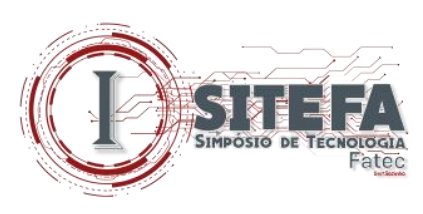

\begin{abstract}
Sustainability is a concept adopted by several productive sectors, which seeks to meet socially desired / valued criteria and legal and normative impositions. Within this context there are international certifications and legislation that address these requirements. Council Directive 28/2009 / EC and European Parliament published on 23 April 2009 and Bonsucro (Better Sugarcane Initiative) are important information bases. Given this context, the sugarcane industry has its practices monitored all over the world, and inappropriate productive practices with this new reality interfere in the marketing of its products. However, in order to enable Brazilian producers to meet these external requirements, Bonsucro, the only certification for sugarcane-derived biofuels implemented in Brazil, included some of the requirements of the European Union. The objective of this work is to demonstrate, through a bibliographical research, the importance of analyzing the sustainability gaps based on the Bonsucro Standard to reach the European market of our sugar and ethanol production units. In conclusion, the identification of the advances of the sector towards the sustainability of ethanol production, and the obstacles that still exist, will lead not only to the proposal of actions that make exports feasible, but also actions to develop part of the sector that does not prioritizes the export. The second aspect, which is quite challenging, is based on the proposal to evaluate the shortcomings and propose actions for the sugar and alcohol industry to meet the requirements that will favor market access.
\end{abstract}

Keywords: Sustainability. Bonsucro. Sucroenergético.

\title{
DOI:
}

\section{INTRODUÇÃO}

O debate sobre a sustentabilidade ambiental tem sido ampliado, abarcando, sobretudo, o impacto da produção agrícola impulsionada pela crescente demanda mundial por alimentos e fontes de energia renováveis, o que exige novos conhecimentos sobre como produzir em conformidade com os critérios e padrões considerados sustentáveis (LEHTONEN, 2011; RUVIARO et al., 2012).

A partir do desenvolvimento técnico-científico, novas tecnologias surgiram, tornando possível a tropicalização da agricultura, isto é, permitindo a expansão desta, para áreas do país onde ela não era aplicada. Logo, o agronegócio atingiu novos patamares e aumentou, ainda mais, sua atuação na economia (PESSOA, 2018). Em razão disso, o Brasil é atualmente conhecido como um dos maiores "celeiros" do mundo, à medida que possui potencial para a produção de alimentos em escala mundial (CONTINI; MARTHA JUNIOR, 2010). 


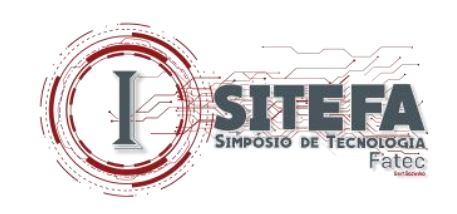

Com destaque na produção de alimentos como cana de açúcar, laranja, café verde, mamões, feijão seco, soja e abacaxi, o Brasil também possui notoriedade quando o assunto é exportação, ao passo que ele é o maior exportador mundial de açúcar bruto centrifugado, carne de frango, café e suco de laranja. Além disso, o agronegócio é o responsável por metade das exportações brasileiras, sendo que em 2017 os produtos mais exportados foram: soja (U\$ 4,72 bilhões,) açúcar, (US\$ 824,22 milhões), celulose (US\$ 527,72 milhões) e carnes (US\$ 1,22 bilhão), contribuindo para o saldo positivo da balança comercial brasileira naquele ano (PESSOA, 2018).

Especificamente na indústria do agronegócio, o setor sucroalcooleiro no Brasil, constituído de usinas de produção de açúcar e álcool, é reconhecido mundialmente pelos seus altos níveis de produtividade nos dois elos da cadeia produtiva (cultivo e colheita), bem como no processamento do açúcar e do álcool e seus derivados (CAMARGO JR.; OLIVEIRA, 2011). Mais recentemente, com a produção de bioeletricidade a partir da queima do bagaço da cana, passou a ser denominado também de setor sucroenergético, sendo os dois termos (sucroalcooleiro e sucroenergético) encontrados na literatura de forma intercambiável.

Janssen e Rutz (2011) e Vieira (2006) ressaltam a experiência brasileira com o etanol, aliada a alguns outros importantes fatores, tais como a alta competitividade natural na produção de cana, bem como a disponibilidade de terras propícias a essa cultura. Tais fatores permitiram ao Brasil assumir papel de liderança nas exportações mundiais de bioetanol, indicando assim a relevância das empresas envolvidas na cadeia de negócios sucroenergética. Além disso, o completo desenvolvimento do processo para a produção comercial de etanol de segunda geração (etanol celulósico) nos próximos anos poderá representar uma mudança transformacional na indústria da cana no país (MATSUOKA; FERRO; ARRUDA, 2009).

Segundo Viana (2013) a sustentabilidade é um conceito adotado por vários setores produtivos, a qual busca atender critérios socialmente desejados/valoráveis e imposições legais e normativas. Dentro deste contexto existem certificações e legislações internacionais que direcionam estas exigências. A Diretiva 28/2009/CE do Conselho e Parlamento Europeu, publicada em 23 de abril de 2009 e a Bonsucro (Better Sugarcane Initiative) atualizada em 11 de março de 2011, são bases importantes de informação.

É a partir da atenção com a vitalidade do atendimento e gestão da sustentabilidade dos processos que caminha a proposta aqui apresentada. O objetivo geral deste trabalho é 


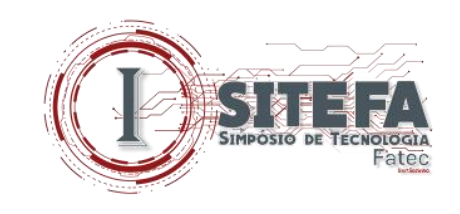

demonstrar através de pesquisa bibliográfica sobre a importância para a Identificação, Análise das lacunas dos principais indicadores de sustentabilidade e proposta de ações para o alcance dos definidos no Padrão de Produção Bonsucro (seis princípios principais) e avaliar o desempenho sustentável da cadeia de produção de sucroenergéticos para exportação para o mercado europeu.

No contexto assim, a questão de pesquisa que é apresentada aqui é: como construir uma Estrutura de Análise de Desempenho Sustentável (ADSucro) para identificar, avaliar e propor ações para o processo de sucroenergéticos levando em consideração os requisitos da norma BONSUCRO? As possíveis respostas devem trazer luz para corroborar, refutar, corrigir ou retroalimentar a hipótese de teste, sendo esta, a estrutura metodológica para o ADSucro de produção sucroenergética para atender os requisitos do mercado europeu através da BONSUCRO.

Verifica-se que no estado da arte sobre ADSucro, metodologia proposta como saída deste artigo é algo novo em que há deficiência de estudos mesmo como proposta semelhante no meio acadêmico e gerencial.

\section{SUSTENTABILIDADE CORPORATIVA E RESPONSABILIDADE SOCIOAMBIENTAL}

Nas últimas décadas a sustentabilidade tem sido apontada como uma das grandes pautas do século XXI (SANTOS; MATSCHUCK, 2015; FRAJ; MATUTE; MELERO, 2015). A literatura que trata do assunto deixa evidências de que a sustentabilidade se tornou o mais urgente desafio, em função das mudanças radicais do modo de se produzir e consumir. Na visão de Santos, Méxas e Meiriño (2017) trata-se de uma tarefa complexa, que necessita de um modelo de gestão inclusivo e abrangente em relação aos interesses, expectativas, e a multiplicidade de agentes envolvidos.

Analisando sobre este assunto, Gladwin, Kennelly e Krause (1995) afirmam que a sustentabilidade constitui uma possibilidade de vantagem competitiva para as organizações, que além de não perderem de vista sua orientação de ganho financeiro, ganham visibilidade e notoriedade por parte dos e fornecedores e consumidores. 


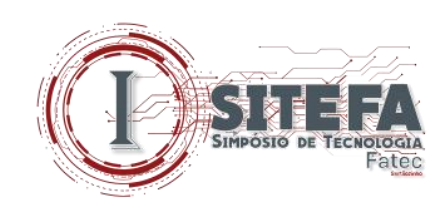

Segundo Callens e Tyteca (1999), o desenvolvimento sustentável pode ser refletido por meio dos diversos fatores econômicos, sociais e ambientais e que devido ao seu papel central nas atividades humanas e no desenvolvimento global dos negócios, as empresas devem desempenhar um papel importante na consecução dos objetivos de sustentabilidade.

Embora não exista um conceito universal sobre desenvolvimento sustentável, alguns autores têm associado à ideia de sustentabilidade com os aspectos ecológicos, conforme pode ser observado nos trabalhos de Hoffman (2000) e Jennings e Zandbergen (1995). Dentre os diversos conceitos encontrados, verificou-se que o mais difundido e, portanto, adotado neste estudo, é respaldado pelo Relatório da Comissão Mundial Sobre o Meio Ambiente e Desenvolvimento - Relatório Brundtland, cuja premissa é a de que "o desenvolvimento sustentável é aquele que atende às necessidades do presente sem comprometer a possibilidade de as gerações futuras atenderem às suas próprias necessidades”, concebido pela COMISSÃO MUNDIAL SOBRE MEIO AMBIENTE E DESENVOLVIMENTO (CMMAD, 1988, p. 46).

Para Whitford e Ruhanen (2010), o desenvolvimento sustentável implica em três aspectos básicos: i) utilização sustentável dos recursos naturais reutilização de materiais; ii) ecossistemas mais saudáveis, em virtude dos menores danos produzidos pelas organizações produtoras e consumidoras; iii) desenvolvimento econômico mais sensibilizados frente às necessidades locais, considerando ganhos que beneficiem a comunidade como um todo. Dentro deste contexto Sachs (2000), propõe que a sustentabilidade contemple as seguintes dimensões, conforme Quadro 1.

\section{Quadro 1 - Dimensões da sustentabilidade}

\begin{tabular}{|c|l|}
\hline \multicolumn{1}{|c|}{ Dimensões } & \multicolumn{1}{c|}{ Descrição } \\
\hline $\begin{array}{c}\text { Sustentabilidade } \\
\text { Social }\end{array}$ & $\begin{array}{l}\text { Envolve a melhoria da qualidade de vida da sociedade, inclusive no que } \\
\text { se refere à distribuição de renda e de diminuição das diferenças sociais. }\end{array}$ \\
\hline $\begin{array}{c}\text { Sustentabilidade } \\
\text { Econômica }\end{array}$ & $\begin{array}{l}\text { Envolve a regularização do fluxo dos investimentos públicos e privados, } \\
\text { de forma que haja compatibilidade entre padrões de produção e consumo, } \\
\text { bem como o acesso à ciência e ao progresso técnico (tecnologia). }\end{array}$ \\
\hline & $\begin{array}{l}\text { No uso dos recursos naturais, os danos à sustentação da vida devem ser } \\
\text { minimizados ou eliminados, por meio de ações como: redução dos } \\
\text { resíduos tóxicos e da poluição (reduzir) reciclagem de materiais e energia }\end{array}$ \\
\hline
\end{tabular}




\begin{tabular}{|c|c|}
\hline $\begin{array}{c}\text { Sustentabilidade } \\
\text { Ecológica }\end{array}$ & $\begin{array}{l}\text { (reciclar), conservação, tecnologias limpas e de maior eficiência, que } \\
\text { permitam reaproveitamento dos recursos, como água, por exemplo, } \\
\text { (reutilizar). }\end{array}$ \\
\hline $\begin{array}{c}\text { Sustentabilidade } \\
\text { Cultural }\end{array}$ & $\begin{array}{l}\text { Refere-se ao respeito aos diferentes valores culturais entre os povos e } \\
\text { incentivo a processos de mudança que acolham aos costumes específicos } \\
\text { de cada região. }\end{array}$ \\
\hline $\begin{array}{c}\text { Sustentabilidade } \\
\text { Espacial }\end{array}$ & $\begin{array}{l}\text { Procura promover o equilíbrio entre o rural e o urbano, procurando } \\
\text { equilibrar as migrações e aderir práticas agrícolas mais inteligentes, não } \\
\text { agressivas à saúde e ao ambiente. }\end{array}$ \\
\hline $\begin{array}{c}\text { Sustentabilidade } \\
\text { Ambiental }\end{array}$ & $\begin{array}{l}\text { Prioriza o equilíbrio dos ecossistemas, a erradicação da pobreza e da } \\
\text { exclusão, respeito aos direitos humanos e integração social. Engloba, } \\
\text { desta forma, todas as dimensões descritas anteriormente. }\end{array}$ \\
\hline
\end{tabular}

Fonte: Elaboro pelos autores com fundamento em Sachs (2000)

\subsection{Setor sucroenergético e certificações}

Compreendido pelas atividades primárias realizadas no estabelecimento e pelas atividades de transformação e de distribuição, o Produto Interno Bruto do agronegócio participa com 23 a 24\% do PIB total do país (PODESTÀ, 2018). Divulgados pelo Instituto Brasileiro de Geografia e Estatística (IBGE), os dados mostram que o PIB brasileiro cresceu em 1,0\% no ano de 2017, sendo esta a primeira alta após dois anos consecutivos de retração (ABAG, 2018). Um dos motivos para esse crescimento veio por meio do agronegócio, já que este avançou 13\% em 2017 (SILVEIRA, 2018).

Com grande potencial energético e larga produção no Brasil, a cana de açúcar vem ganhando cada vez mais espaço no mercado. A produção de cana de açúcar é uma das principais culturas da economia brasileira, sendo que o Brasil é o maior produtor da mesma, além de ser também o primeiro na produção de açúcar e etanol (LIMA, 2016).

Juntamente com o aumento da demanda interna, o Brasil visa atender também, grande parte da economia global por etanol e assim consolidar um mercado internacional (GILIO; CASTRO, 2016). 


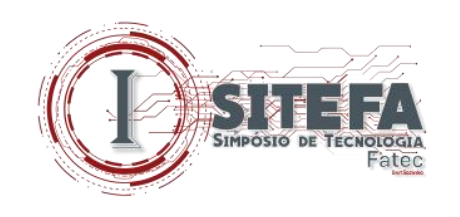

Segundo Rodrigues et al (2014) as certificações têm adquirido importância no setor sucroenergético, como resposta às pressões ambientais exercidas pelas legislações sobre os setores produtivos. Existem três vertentes de argumentos favoráveis às certificações, a saber, i) promovem um prêmio pago pelo preço do produto, apesar de ser de difícil comprovação estatística; ii) são um passo para a otimização do processo produtivo, melhorando a relação entre produtores e consumidores, contribuindo para a redução das incertezas e iii) são necessárias para atender mercados consumidores com regras mais complexas, como Estados Unidos, União Europeia e Japão.

A certificação Bonsucro foi criada no ano de 2011, se trata de uma iniciativa global sem fins lucrativos voltada à produção e à gestão de cana-de-açúcar sustentável, portanto específica para o setor sucroenergético. Além da unidade produtora de açúcar e etanol, as indústrias que utilizam o açúcar e etanol certificados também podem obter o selo, após processo de auditoria semelhante ao das usinas. Segundo Rodrigues et al (2014) a certificação Bonsucro surgiu através da Better Sugarcane Initiative, uma associação dedicada a reduzir os impactos ambientais e sociais da produção de cana de açúcar, sendo exclusivamente voltada ao setor sucroenergético

A certificação Bonsucro ("Better Sugar Cane Initiative") possui duas divisões, com focos diferentes entre si. A primeira, denominada Padrão de Produção Bonsucro, é voltada somente para as unidades produtoras de açúcar e etanol. $82 \%$ das certificações mundiais do Padrão de Produção são de usinas de cana-de-açúcar brasileiras.

Dessa maneira, a Bonsucro visa, em particular, segundo Ismail, Rossi e Geiger (2011).

- definir o desempenho mundialmente aplicável baseado nos princípios, critérios, indicadores e padrões para a produção de cana;

- promover melhorias mensuráveis nos principais impactos econômicos, ambientais e sociais da produção de cana e processamento primário;

- desenvolver um sistema de certificação que permite a produtores, compradores e outras pessoas envolvidas nos negócios de açúcar e etanol, obterem produtos derivados da cana que tenham sido produzidos de acordo com critérios transparentes e mensuráveis

Assim, a certificação Bonsucro é homologada por meio de auditorias realizadas por certificadoras acreditadas pela Bonsucro, a exemplo da TÜV Rheinland do Brasil Ltda, um dos maiores organismos certificadores no Brasil e no mundo e para ser obtida, é necessário que 


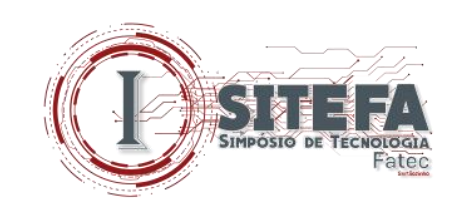

$80 \%$ dos indicadores estejam em conformidade, além do atendimento total dos cinco critérios essenciais (CARVALHO, 2010).

\subsection{A certificação BONSUCRO e estrutura de análise de desempenho sustentável (ADSucro)}

Bonsucro é uma associação multi-stakeholder criada com o objetivo de reduzir os impactos ambientais e sociais da produção de cana-de-açúcar, através do desenvolvimento de um padrão e programa de certificação para transformar a indústria da cana (BATTISTELLA; HERGART, 2013). O padrão Bonsucro é o primeiro padrão métrico global para cana de açúcar. Permite demonstrar por meio de impactos mensuráveis que sua empresa apoia os direitos humanos e está preocupada em implementar práticas ambientalmente corretas.

Atesta práticas sustentáveis em toda a cadeia produtiva e possibilita a exportação de derivados de cana-de-açúcar para países da Ásia e da União Europeia. Assegura ainda o cumprimento da legislação, o respeito aos direitos humanos e trabalhistas, a garantia da sustentabilidade na produção, a preservação da biodiversidade e dos serviços do ecossistema, além da produtividade e da melhoria contínua dos processos de produção.

Battistella e Hergart (2013) procuraram evidenciar a importância da certificação Bonsucro e dos mecanismos regulatórios pesquisados para atender a demanda do mercado nacional e internacional do etanol de cana-de-açúcar. Esse estudo é importante na medida em que a demanda por biocombustíveis e pressão dos mercados pela sustentabilidade vem crescendo com o passar dos anos, com a necessidade crescente por regulamentação desses produtos.

No processo de certificação a certificação é concedida à usina de açúcar e etanol, mas a avaliação é baseada em auditoria da usina e da área agrícola fornecedora de cana. Os operadores econômicos "pós-porteira" da usina, como portos, armazéns e traders, podem ser certificados também pelo Padrão BONSUCRO de Cadeia de Custódia.

Seus principais objetivos são:

- Definir princípios, critérios, indicadores e padrões para a produção de cana de açúcar com base em desempenho; 


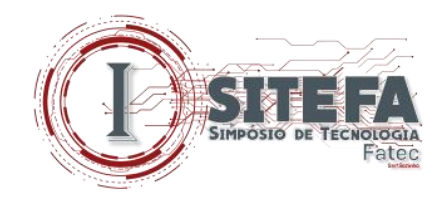

- Promover melhorias mensuráveis nos impactos econômicos, ambientais e sociais da produção de cana e processamento, e

- Desenvolver um sistema de certificação que permite aos produtores, compradores e outros envolvidos nos negócios de açúcar e etanol obter produtos derivados da cana que tenham sido produzidos de acordo com os critérios acordados, críveis, transparentes e mensuráveis.

O Quadro 2 apresenta de forma sistematizada, os princípios e os respectivos critérios e indicadores do sistema de certificação Bonsucro.

\section{Quadro 2 - Critérios da Bonsucro}

\begin{tabular}{|c|c|c|}
\hline Princípios & Critérios & Indicadores \\
\hline $\begin{array}{l}\text { Cumprimento da } \\
\text { lei }\end{array}$ & $\begin{array}{l}\text { 1. Cumprir as leis relevantes e } \\
\text { aplicáveis } \\
\text { 2. Demonstrar titularidade das } \\
\text { terras de acordo com práticas } \\
\text { e leis nacionais }\end{array}$ & $\begin{array}{l}\text { 1. Leis nacionais e convenções internacionais relevantes } \\
\text { cumpridas } \\
\text { 2. O direito de uso da terra deve ser comprovado, sem ser } \\
\text { objeto de legítima contestação pelas comunidades locais } \\
\text { que tenham direitos demonstráveis }\end{array}$ \\
\hline \multirow[t]{5}{*}{$\begin{array}{l}\text { 2.. Respeito aos } \\
\text { direitos humanos } \\
\text { e trabalhistas }\end{array}$} & $\begin{array}{l}\text { 2. Cumprir com as convenções } \\
\text { da OIT que regem sobre o } \\
\text { trabalho infantil, o trabalho } \\
\text { forçado, a discriminação e a } \\
\text { liberdade de associação e o } \\
\text { direito de negociar } \\
\text { coletivamente }\end{array}$ & $\begin{array}{l}\text { 3. Idade mínima dos trabalhadores } \\
\text { 4. Ausência de trabalho forçado ou obrigatório } \\
\text { 5. Ausência de discriminação } \\
\text { 6. Respeitar o direito de todos os trabalhadores de } \\
\text { formarem e se associarem a sindicatos e/ou de negociação } \\
\text { coletiva de acordo com a lei }\end{array}$ \\
\hline & $\begin{array}{l}\text { 3. Aplicar os direitos } \\
\text { humanos e trabalhistas da BSI } \\
\text { aos fornecedores e } \\
\text { contratados }\end{array}$ & $\begin{array}{l}\text { 7. Percentagem de contratados e principais fornecedores } \\
\text { que demonstraram que cumprem os direitos humanos e } \\
\text { trabalhistas }\end{array}$ \\
\hline & $\begin{array}{l}\text { 4. Assegurar um ambiente de } \\
\text { trabalho seguro e saudável em } \\
\text { operações de trabalho }\end{array}$ & $\begin{array}{l}\text { 8. Frequência de acidentes com afastamento } \\
\text { 9. Avaliação dos principais riscos para a saúde e } \\
\text { segurança, e a implementação de medidas de mitigação de } \\
\text { risco } \\
\text { 10. EPIs fornecidos e usados por todos os trabalhadores } \\
\text { 11. Treinamento em saúde e segurança } \\
\text { 12. Disponibilidade em quantidade suficiente de água } \\
\text { potável segura para cada trabalhador no campo e/ou na } \\
\text { indústria } \\
\text { 13. Acesso a primeiros socorros e sistemas de respostas a } \\
\text { emergência }\end{array}$ \\
\hline & $\begin{array}{l}\text { 5. Prover os trabalhadores } \\
\text { com pelo menos o salário } \\
\text { mínimo nacional }\end{array}$ & $\begin{array}{l}\text { 14. Razão entre o menor salário inicial, incluindo } \\
\text { benefícios, e o salário mínimo nacional, conforme } \\
\text { definido em lei }\end{array}$ \\
\hline & 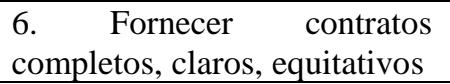 & 15. Existência de um contrato ou documento equivalente \\
\hline $\begin{array}{l}3 . \\
\text { Gerenciamento } \\
\text { da eficiência dos } \\
\text { insumos e } \\
\text { processamento }\end{array}$ & $\begin{array}{l}\text { 7. Monitorar a eficiência da } \\
\text { produção e do processo; medir } \\
\text { os impactos da produção e do } \\
\text { processamento com vistas a } \\
\text { melhorias ao longo do tempo }\end{array}$ & $\begin{array}{l}\text { 16. Total de matéria-prima consumida por quilo de } \\
\text { produto } \\
\text { 17. Produtividade da cana-de-açúcar } \\
\text { 18. Percentual de horas perdidas em relação horas } \\
\text { trabalhadas }\end{array}$ \\
\hline
\end{tabular}




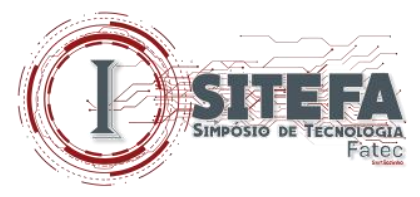

\begin{tabular}{|c|c|c|}
\hline \multirow[t]{2}{*}{$\begin{array}{l}\text { para aumentar a } \\
\text { sustentabilidade }\end{array}$} & & $\begin{array}{l}\text { 19. Eficiência total da usina em termos de tempo. } \\
\text { 20. Índice de desempenho da fábrica } 21 \text {. Eficiência } \\
\text { industrial }\end{array}$ \\
\hline & $\begin{array}{l}\text { 8. Monitorar as emissões de } \\
\text { gases de efeito estufa visando } \\
\text { minimizar os impactos na } \\
\text { mudança climática }\end{array}$ & $\begin{array}{l}\text { 22. Contribuição ao aquecimento global por unidade-peso } \\
\text { produzido }\end{array}$ \\
\hline \multirow[t]{2}{*}{$\begin{array}{l}\text { 4. Gerenciamento } \\
\text { ativo da } \\
\text { biodiversidade e } \\
\text { ecossistemas }\end{array}$} & $\begin{array}{l}\text { 9. Avaliar os impactos das } \\
\text { agroindústrias } \quad \text { sobre a } \\
\text { biodiversidade e ecossistemas }\end{array}$ & $\begin{array}{l}\text { 23. Demanda de oxigênio aquático por unidade-peso de } \\
\text { produto } \\
\text { 24. Percentual de Área de Preservação Permanente-APP } \\
\text { 25. Existência de um Plano de Gestão Ambiental levando } \\
\text { em conta as espécies, os habitats e os ecossistemas } \\
\text { ameaçados } \\
\text { 26. O uso de subprodutos não impacta os usos tradicionais } \\
\text { e o equilíbrio de nutrientes e a matéria orgânica do solo } \\
\text { 27. Aplicação de fertilizantes de acordo com a análise do } \\
\text { solo e folhas } \\
\text { 28. Fertilizantes de Nitrogênio e Fósforo aplicados por } \\
\text { hectare por ano. } \\
\text { 29. Herbicidas e pesticidas aplicados por hectare por ano }\end{array}$ \\
\hline & $\begin{array}{l}\text { 10. Implementar medidas para } \\
\text { mitigar os impactos adversos } \\
\text { quando identificados }\end{array}$ & $\begin{array}{l}\text { 30. Plano documentado e implementação de medidas de } \\
\text { mitigação }\end{array}$ \\
\hline \multirow[t]{7}{*}{$\begin{array}{lr}5 . & \text { Melhoria } \\
\text { contínua } & \text { das } \\
\text { áreas-chave do } \\
\text { negócio }\end{array}$} & $\begin{array}{l}\text { 11. Treinar empregados e } \\
\text { outros trabalhadores em todas } \\
\text { as áreas do seu serviço, e } \\
\text { desenvolver suas habilidades } \\
\text { gerais }\end{array}$ & $\begin{array}{l}\text { 31. Gasto com treinamento dos empregados como } \\
\text { porcentagem do gasto com a folha de pagamento }\end{array}$ \\
\hline & $\begin{array}{l}\text { 12. Melhorar continuamente } \\
\text { as condições dos recursos de } \\
\text { solo e da água }\end{array}$ & $\begin{array}{l}\text { 32. Consumo líquido de água por unidade-peso de produto } \\
\text { 33. Porcentagem do solo coberto por palha de cana-de- } \\
\text { açúcar após a colheita } 34 \text {. Superfície do solo arado } \\
\text { mecanicamente por ano } \\
\text { 35. Porcentagem dos campos com amostras que mostram } \\
\text { limites aceitáveis de pH }\end{array}$ \\
\hline & $\begin{array}{l}\text { 13. Melhorar continuamente a } \\
\text { qualidade da cana-de-açúcar e } \\
\text { dos produtos da usina }\end{array}$ & $\begin{array}{l}\text { 36. Conteúdo de açúcar teoricamente recuperável (ATR) } \\
\text { na cana-de-açúcar } 37 \text {. Total de açúcares fermentáveis } \\
\text { contidos na cana-de-açúcar, expresso como açúcar total } \\
\text { invertido (TSAI) }\end{array}$ \\
\hline & $\begin{array}{l}\text { 14. Promover a eficiência } \\
\text { energética }\end{array}$ & $\begin{array}{l}\text { 38. Uso total líquido da energia primária por quilo de } \\
\text { produto } \\
\text { 39. Energia usada no transporte da cana-de-açúcar por } \\
\text { tonelada transportada } 40 \text {. Energia primária utilizada por } \\
\text { tonelada de cana-de-açúcar }\end{array}$ \\
\hline & $\begin{array}{l}\text { 15. Reduzir as emissões e os } \\
\text { efluentes e promover a } \\
\text { reciclagem dos fluxos de } \\
\text { resíduos }\end{array}$ & $\begin{array}{l}\text { 41. Carga de acidificação atmosférica por unidade-peso de } \\
\text { produto } \\
\text { 42. Resíduos sólidos não perigosos por tonelada de cana- } \\
\text { de-açúcar }\end{array}$ \\
\hline & $\begin{array}{l}\text { 16. Promover a pesquisa } \\
\text { efetiva e focada, o } \\
\text { desenvolvimento e a extensão } \\
\text { especializada }\end{array}$ & $\begin{array}{l}\text { 43. Custo de Pesquisa e Extensão como porcentagem das } \\
\text { vendas }\end{array}$ \\
\hline & $\begin{array}{l}\text { 17. Expandir áreas verdes ou } \\
\text { novos projetos de cana a partir } \\
\text { de critérios preestabelecidos } \\
\text { de forma transparente, }\end{array}$ & $\begin{array}{l}\text { 44. Estar em conformidade com uma AISA reconhecida } \\
\text { 45. Áreas de Alto Valor de Conservação usadas como } \\
\text { porcentagem da área total impactada por um novo projeto } \\
\text { ou expansão }\end{array}$ \\
\hline
\end{tabular}


participativa que leve em consideração os impactos sociais e ambientais, através de uma avaliação de impacto socioambiental (AISA).

18. Assegurar engajamento e processos transparentes, consultivos e participativos com todos os stakeholders relevantes

19. Promover a sustentabilidade econômica
46. Existência de um mecanismo reconhecido para resolução de reclamações e disputas, para todos os stakeholders

47. Porcentagem de reuniões de engajamento de stakeholders onde um acordo foi alcançado por meio de um processo motivado pelo consenso

48. Valor adicionado/por tonelada de cana-de-açúcar

Fonte: Bonsucro (2018).

Desempenho sustentável pode ser definido como a informação oferecida por um conjunto de indicadores que permite comparar entre si, ou a partir de um referencial conceitual, os requisitos sustentáveis em área ou setores de uma empresa ou entre empresas do mesmo grupo ou região. Entretanto, para possibilitar que os produtores brasileiros possam atender também a essas exigências externas, o Bonsucro (2018) única certificação para biocombustíveis derivados de cana-de-açúcar implementada no Brasil - incluiu algumas das exigências da União Europeia. Mas, por pressão dos produtores, a certificação optou por não tratar ou abordar de forma genérica questões que ainda estão sendo discutidas e para as quais ainda não há uma metodologia bem definida para apurar o cumprimento.

"Hoje, a maior parte dos certificados pela Bonsucro são os grandes produtores de canade-açúcar, que já têm uma série de outras certificações de gestão e qualidade, mas que ainda não têm 100\% da produção certificada", cita ALISSON (2012). Entretanto, na avaliação de autor, um dos principais desafios para expansão dessa certificação no país será aumentar sua abrangência e adesão pelos pequenos e médios produtores e terceiros fornecedores de cana-deaçúcar, que têm maior dificuldade em cumprir alguns pontos da legislação trabalhista e ambiental brasileira.

A Estrutura de Análise de Desempenho Sustentável do Bonsucro (ADSucro), dessa maneira, é um processo que objetiva facilitar o processo de decisão gerencial sobre o desempenho sustentável de uma organização através da seleção de indicadores, coleta, análise de dados, análise das lacunas atuais das organizações para o alcance de tal certificação, considerando e avaliando as informações geradas de acordo com os critérios de sustentabilidade, divulgação, revisão e aperfeiçoamento desse processo. 


\section{PROCEDIMENTOS METODOLÓGICOS}

A pesquisa realizada e aqui apresentada pode ser classificada como bibliográfica, pois sua fonte de dados foi extraída de Anais de Congressos, Revistas, Livros, sites de referência no setor sucroenergético e órgãos de normatização/regulação.

Primeiramente, foi pesquisado e analisado a certificação Bonsucro e os mecanismos regulatórios, tendo como base United States Environmental Protection Agency (EPA), California Air Resources Board (CARB) e European Union - Renewable Energy Directive (EU-RED) e, posteriormente, realizado um estudo de caso da empresa XYZ Energia, que atualmente é a principal fabricante de etanol de cana-de-açúcar do país e a maior exportadora individual de açúcar de cana no mercado internacional. A metodologia utilizada foi a pesquisa exploratória, através da revisão da literatura e pesquisa documental, além do estudo de caso.

O método de pesquisa utilizado neste artigo foi o estudo de caso. Conforme sugerido por Yin (2015), utiliza-se o estudo de caso como estratégia de pesquisa em muitas situações, como em pesquisas em administração, sociologia, estudos organizacionais e gerenciais. Justificando o modelo de pesquisa adotado por esta pesquisa foi realizado um estudo de caso.

A abordagem realizada nesta pesquisa é de caráter qualitativo, para maior adequação aos objetivos propostos para este estudo (YIN, 2015).

\section{RESULTADOS E DISCUSSÃO}

Com o objetivo de entender o que está sendo estudado e proposto sobre indicadores de sustentabilidade no setor sucroenergético, foram identificados esforços que apresentam, por meio de estudos sobre fundamentos ou estudos aplicados, objetivos e desafios que buscam responder as inquietações de hoje: como atingir a sustentabilidade.

A Bonsucro é uma associação mundial que contempla vários stakeholders (grupos de interesse como comerciantes de açúcar, investidores, produtores e Organizações Não Governamentais) criada para reduzir os impactos ambientais e sociais da cana de açúcar, através da concepção de um padrão e um programa para transformar a indústria da cana (ISMAIL; ROSSI; GEIGER, 2011). A adesão favorece a conquista de padrões elevados de excelência de produção de cana, muito acima do que é determinado pela legislação ambiental nacional. 


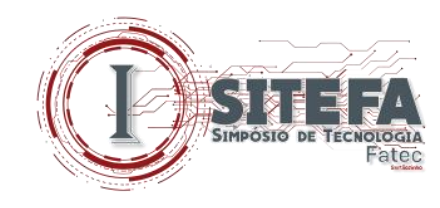

A Bonsucro (2018) certifica as indústrias do setor sucroenergético que atendem a pelo menos $80 \%$ dos critérios estabelecidos nos seus cinco princípios, que são:

1. Obedecer a lei;

2. Respeitar os direitos humanos e normas de trabalho;

3. Gerenciar o fornecimento, produção e processamento;

4. Gerenciar biodiversidade e serviços ambientais, e;

5. Melhorar as áreas de impacto do negócio.

Esta certificação visa salientar a importância para a identificação, análise das lacunas dos principais indicadores de sustentabilidade e proposta de ações para o alcance dos objetivos definidos no Padrão de Produção Bonsucro.

No cenário apresentado, muitos autores propõem estruturas e metodologias de ADA (Avaliação de Desempenho Ambiental), ou de Desempenho ambiental, mas poucas em relação à sustentabilidade e propondo assim adequação da estrutura de modo não genérico. Pode-se verificar, no entanto, que não existem trabalhos, dentro destas diretrizes metodológicas aplicadas à produção sucroenergética, considerando a Norma BONSUCRO, seja brasileira ou mundial.

Como exemplo e através das pesquisas realizadas em artigos e levantamento em bases de dados, constatou-se que determinados autores aplicaram estudos sobre a certificação BONSUCRO, portanto no próximo parágrafo é apresentado um estudo realizado pelo autor Viana (2013) que destaca as dificuldades na aplicação desta certificação em usinas sucroenergetica.

Viana (2013) desenvolveu uma pesquisa com objetivo de avaliar a situação das usinas do estado de Minas Gerais quanto ao atendimento a critérios de sustentabilidade. O embasamento dessa avaliação foi realizado a partir da abordagem dos cinco princípios contidos na Bonsucro, e que também se encontram na Diretiva 28/2009 da União Europeia. O trabalho foi realizado a partir de um estudo de multicaso, composto por quatro usinas, nas quais dados foram coletados por meio de questionários. Além das usinas, a Associação das Indústrias Sucroenergéticas de Minas Gerais (SIAMIG) também foi entrevistada. Os resultados apontam que as usinas estudadas ainda não estão preparadas para receber a certificação Bonsucro, pois não atendem a $80 \%$ dos indicadores estabelecidos, que é o mínimo exigido. A partir da aplicação da metodologia SWOT, identificou- se que as usinas possuem muitos pontos fortes e 


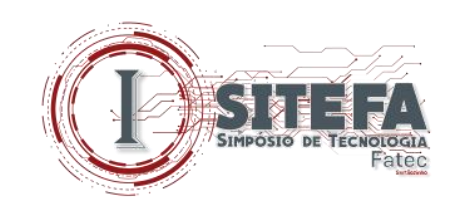

oportunidades, porém são nos pontos fracos, que as prejudicam atender aos indicadores de sustentabilidade, são necessários investimentos maiores que, aliados aos pontos fortes, contribuirão para garantir a sustentabilidade do setor. Ao longo do estudo observou-se que as usinas estão se adaptando às legislações existentes e buscando essas certificações, porém ainda

precisam se qualificar e adotarem uma postura mais preventiva e não corretiva, para assim acelerar este processo de adequação.

Segundo a BONSUCRO (2018) já existem 61 usinas certificadas em 9 países (46 usinas em Brasil), 28 certificados de cadeia de custódia em 14 países, 3 programas de produtores comparados, com 4,571,662 toneladas de açúcar certificados e 2,835,219 $\mathrm{m}^{3}$ de etanol certificado.

Outro fator de análise é a certificação para pequenos produtos. Os pequenos agricultores são um componente crucial em muitas indústrias de cana-de-açúcar em todo o mundo. Para garantir que os pequenos produtores tenham as mesmas oportunidades de melhoria de desempenho que outros produtores, a Bonsucro está embarcando em uma revisão do Padrão de Produção Bonsucro e do Sistema de Certificação no contexto dos pequenos produtores.

\section{CONCLUSÃO}

Diante das considerações iniciais, busca-se com esta revisão bibliográfica fornecer premissas para levantar a situação atual da sustentabilidade nas indústrias de açúcar e etanol do Estado de São Paulo, utilizando como balizamento os indicadores exigidos pela legislação internacional, em especial os da Bonsucro e Diretiva da União Europeia 28/2009. Tendo em vista que o atendimento a estas normativas tem sido buscado pelas usinas sucroalcooleiras de todo o mundo, sente-se a necessidade de verificar se as usinas de São Paulo, poderiam ou não expandir seus mercados (nacional e internacional) caso a Bonsucro e Diretiva da União Europeia passassem a ser exigidas hoje pelos clientes dessas usinas. Questiona-se se estas têm condições de atender estes critérios de sustentabilidade, ou se já atendem e podem receber o selo Bonsucro.

Ajustar os procedimentos ou mesmo relatar os avanços conseguidos quanto a sustentabilidade, é extremamente importante para as usinas canavieiras, já que estas, em muitos fóruns, como por exemplo Rio + 20 (ONU, 2012), têm sido responsabilizadas por ações 


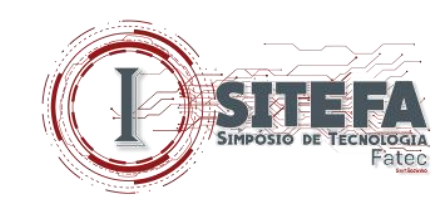

negativas ao ambiente e à sociedade, e com isso a cobrança por esclarecimentos e provas de atendimento a normas sobre sustentabilidade têm sido cada vez mais fortes.

Assim, ao avaliar os fatores citados, esperou-se traçar um perfil das usinas estudadas e identificação das situações das mesmas quanto à sustentabilidade, especificadamente quanto ao atendimento à Bonsucro e Diretiva da União Europeia. Dessa forma, a proposta foi apoiar o desenvolvimento e a estruturação do setor, além de promover as ações realizadas pelas usinas de São Paulo. Diante do atual cenário mundial, no qual a substituição, ainda que parcial, dos combustíveis fósseis por biocombustíveis é prioridade, o desenvolvimento de estudo sobre o atendimento do setor sucroalcooleiro brasileiro a requisitos para a sustentabilidade da produção de etanol, é de grande contribuição para permitir que as exportações brasileiras desse biocombustível se viabilizem.

Paralelamente, a identificação dos avanços do setor rumo à sustentabilidade da produção de etanol, e dos obstáculos ainda existentes, conduzirá não só à proposição de ações que viabilizem as exportações, mas também ações para desenvolver parte do setor que não prioriza a exportação. $\mathrm{O}$ ineditismo da pesquisa proposta está fundamentado em dois aspectos principais. $\mathrm{O}$ primeiro refere-se à novidade do tema em si e a sua recente discussão pelos mais diversos atores em âmbito internacional. Tal característica ficou evidenciada na pesquisa bibliográfica realizada preliminarmente, a qual revelou um número relativamente baixo de artigos, teses ou dissertações que abordam o tema com tal enfoque. O segundo aspecto, bastante desafiador, baseia-se na proposta de avaliação das lacunas, e propor ações para o setor sucroalcooleiro quanto ao atendimento a requisitos que lhe favorecerão no acesso a mercados. Não foi identificada, durante o levantamento bibliográfico, proposta semelhante nos trabalhos acadêmicos pesquisados.

\section{REFERÊNCIAS}

ABAG. PIB do agro tem melhor resultado da série do IBGE em 2017. Disponível em: < http://www.abag.com.br/sala_imprensa/interna/abag-pib-do-agro-tem-melhor-resultado-1>. Acesso em: 13 abr. 2018.

ALISSON, E. Estudo aponta gargalos para implementar certificações de biocombustíveis para aviação no Brasil. Agencia Fapesp. 2012. 


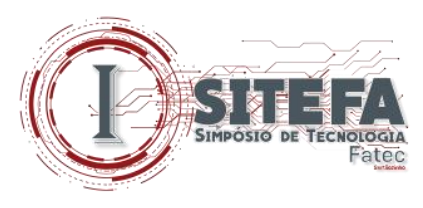

BATTISTELLA, L.; HERGERT, T.K. Sistema de certificação de etanol Bonsucro e mecanismos regulatórios: estudo de caso Raízen energia S/A. Trabalho de Conclusão de Curso apresentado como Gestão do Agronegócio à Faculdade de Ciências Aplicadas da Universidade Estadual de Campinas. 2013.

BONSUCRO. 2015. Padrão de Produção Bonsucro. Disponível em http://bonsucro.com/site/productionstandard/>. Acesso em: 15 nov. 2018.

CALLENS, I.; TYTECA, D. Towards Indicators of Sustainable Development for Firms: Concepts and Definitions. Ecological Economics. v. 28, p. 41-53, 1999. http:// dx.doi.org/10.1016/S0921-8009(98)00035-4

CAMARGO Jr., A. S.; OLIVEIRA, M. M. B.. Eficiência econômica no setor sucroalcooleiro: uma análise de algumas usinas do estado de São Paulo. Organizações Rurais \& Agroindustriais, Lavras, v.13, n.3, p.330-343, 2011.

CARVALHO, L.C.C. Evolução do Setor Cana no Estado de São Paulo. In: Bioetanol de cana-de-açúcar - P\&D para Produtividade e Sustentabilidade. Coordenador: CORTEZ, L.A.B. Blucher; Fapesp. p.53-61. 2010.

CONTINI, E.; MARTHA JUNIOR, G. B. Brazilian agriculture, its productivity and change. Bertebos Conference on "Food security and the futures of farms: 2020 and toward 2050". Falkenberg: Royal Swedish Academy of Agriculture and Forestry, August 29-31, 2010.

\section{COMISSÃO MUNDIAL SOBRE MEIO AMBIENTE E DESENVOLVIMENTO}

(CMMAD). Nosso futuro comum. Rio de Janeiro: Fundação Getúlio Vargas, 1998.

FRAJ, E; MATUTE, J; MELERO, I. Environmental strategies and organizational competitiveness in the hotel industry: The role of learning and innovation as determinants of environmental success. Tourism Management, v. 46, p.30-42, fev., 2015.

GILIO, L.; CASTRO, N. R. Avaliação de aspectos limitantes ao crescimento do etanol e o setor sucroenergético no Brasil. Revista Eletrônica de Energia, 6(1).2017.

GLADWIN, T. N., KENNELLY, J. J., KRAUSE, T. S. Shifting paradigms for sustainable development: implications for management theory and research. Academy of Management Review, 20 (4): 874-907, 1995.

HOFFMAN, A. J. Environmental and Social Issues into Corporate Practice. Environment, 2(5): 22, June, 2000.

ISMAIL, M., A. ROSSI, N. GEIGER. A compilation of bioenergy sustainability initiatives Retrieved. 2011. Disponível em: <http://www.fao.org/bioenergy/28190-

01db4fcd51560954e617923620b75c5e7.pdf>. Acesso em: 20 out. 2018. 


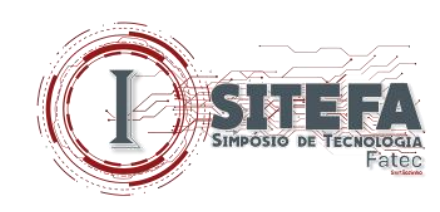

JANSSEN, R; RUTZ, D. D.. Sustainability of biofuels in Latin America: risks and opportunities. Energy Policy, n.39, p.5717-5725, 2011.

JENNINGS, P. D., ZANDBERGEN, P.A. Ecologically Sustainable Organizations: an Institutional Approach. Academy of Management Review, 20(4): 1015-1052, 1995.

LEHTONEN, M. (2011) "Social sustainability of the Brazilian bioethanol: Power relations in a centre-periphery perspective”, Biomass \& Bioenergy n 35, pp. 2425-2434, ISSN: 09619534.

LIMA, M. P. A produção da cana-de-açúcar no brasil-uma análise dos impactos socioeconômicos. Anais do Seminário de Pesquisa, Pós-Graduação, Ensino e Extensão do Câmpus Anápolis de CSEH (SEPE), 2(1).2016.

MATSUOKA, S.; FERRO, J.; ARRUDA, P.. The Brazilian experience of sugarcane ethanol industry. In Vitro Cell. Dev. Biol. - Plant, n.45, p.372-381, 2009.

ORGANIZAÇÃO DAS NAÇÕES UNIDAS (ONU). 2012. Adoção do acordo de Paris. Disponível em:< https://nacoesunidas.org/acordodeparis/>. Acesso em: 04 nov. 2017.

PESSOA, A. S. A importância do agronegócio para o Brasil. 2018. Disponível em: $<$ http://www.iicabr.iica.org.br/produtos_tecnicos/a-importancia-do-agronegocio-para-o-brasil2/>. Acesso em: 12 abr. 2018.

PODESTÀ, I. Agropecuária puxa o PIB de 2017. Disponível em:

<http://www.agricultura.gov.br/noticias/agropecuaria-puxa-o-pib-de-2017>. Acesso em: 13 abr. 2018.

RODRIGUES, A.M.; REBELATO, M. G.; PAIXÃO, R. B. S. ; ZEVIANI, C.H. Gestão ambiental no setor sucroenergético: uma análise comparativa. Revista Produção Online, Florianópolis, SC, v.14, n. 4, p. 1481-1510, out./dez. 2014.

RUVIARO, C. F. et al. Life cycle assessment in Brazilian agriculture facing worldwide trends. Journal of Cleaner Production, Amsterdam, v. 28, p. 9-24, June 2012.

SACHS, I. Caminhos para o desenvolvimento sustentável. Rio de Janeiro: Garamond, 2000.

SANTOS, R.A; MATSCHUCK, T.C., A Sustentabilidade e a Cadeia Produtiva Hoteleira: um Estudo de Caso no JW Marriott, Rio de Janeiro. Rev. Turismo Visão Ação, v. 17,n. 2, p. 444-474, mai.-ago. 2015.

SANTOS, R. A.; MÉXAS, M. P.; MEIRIÑO, M. J. Sustainability and hotel business: criteria for holistic, integrated and participative development. Journal of Cleaner Production, v. 142, p. 217-224, 2017. 


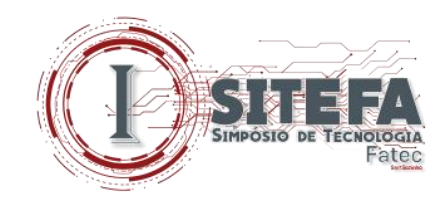

SILVEIRA, D. PIB brasileiro cresce 1,0\% em 2017, após 2 anos de retração. Disponível em: <https://g1.globo.com/economia/noticia/pib-brasileiro-cresce-10-em-2017-apos-2-anosde-retracao.ghtml>. Acesso em: 13 abril 2018.

VIANA, K. R. de O. Sustentabilidade no Setor Sucroenergético. Dissertação de mestrado. Universidade Federal de Viçosa, março de 2013.

VIEIRA, M. C. A.. Setor sucroalcooleiro brasileiro: evolução e perspectivas. Brasília: BNDES, 2006.

WHITFORD, M.M., RUHANEN, L. N. Australian indigenous tourism policy: practical and sustainable policies? Journal of Sustainable Tourism, 18 (4): 475-496, 2010.

YIN, R. K. Estudo de caso: planejamento e métodos. 5. ed. Porto Alegre: Bookman, 2015. 